\title{
Estradiol Affects Epstein-Barr Virus Reactivation-Induced Thyrotropin Receptor Antibody and Immunoglobulin Production in Graves' Disease Patients and Healthy Controls
}

\author{
Sayuri Hara, Keiko Nagata,' Keisuke Kumata, Michiko Matsushita, Satoshi Kuwamoto, \\ Masako Kato, and Kazuhiko Hayashi ${ }^{1}$
}

\begin{abstract}
Epstein-Barr virus (EBV) is a gamma-herpesvirus persisting mainly in human B lymphocytes. EBV reactivation induces host cells to differentiate into plasma cells and is related to autoimmune diseases. Graves' disease, an autoimmune hyperthyroidism, is caused by the thyrotropin receptor antibody (TRAb), which overstimulates thyroid stimulating hormone receptor. The disease occurs predominantly in women, which suggests involvement with estrogen. Graves' disease patients and healthy controls have EBV-infected lymphocytes with TRAb on the surface $(\mathrm{TRAb}(+) \mathrm{EBV}(+)$ cells) in peripheral blood mononuclear cells (PBMCs). TRAb can be produced by reactivation of EBV in vitro, which is an alternative system of antibody production. In this study, we cultured PBMCs from Graves' disease patients and healthy controls with 0,1 , and $100 \mathrm{nM}$ estradiol, corresponding to control, midluteal, and pregnancy levels, respectively, and analyzed the levels of $\mathrm{TRAb}$, total-IgG, and total-IgM during EBV reactivation. We found that $1 \mathrm{nM}$ estradiol increased TRAb levels and $100 \mathrm{nM}$ estradiol slightly lowered them in both patients and controls. In patients, IgM production at $100 \mathrm{nM}$ estradiol was significantly lower than that at $0 \mathrm{nM}$ estradiol $(p=0.028)$. Estradiol increased the ratio of IgG production to immunoglobulin $\mathrm{G}(\mathrm{IgG})$ and immunoglobulin $\mathrm{M}(\mathrm{IgM})$ production $(\mathrm{IgG} / \mathrm{IgG}+\operatorname{IgM})$, which suggested an increase in class switch recombination in the process of EBV reactivation-induced Ig production. Moreover, TRAb production was stimulated by a midluteal level of estradiol and was suppressed by a pregnancy level of estradiol in controls and patients. These results were consistent with premenstrual worsening and maternity improving of autoimmune diseases, including Graves' disease.
\end{abstract}

Keywords: estradiol, EBV reactivation, Ig production, Graves' disease

\section{Introduction}

M OST AUTOIMMUNE DISEASES predominantly occur in women and are influenced by various factors, including reproductive function, genetics $(14,16)$, and sex hormones $(5,6,19,20)$. Estrogen binds to estrogen receptors (ERs), $\mathrm{ER} \alpha$ and $\mathrm{ER} \beta$, and regulates the menstrual cycle and maternity. Estrogen triggers distinct signaling pathways (6) and can stimulate antibody production from B cells (20). Estradiol is the most potent estrogen. The levels of immunoglobulin $\mathrm{G}(\operatorname{IgG})$ and immunoglobulin $\mathrm{M}(\operatorname{IgM})$ in human peripheral blood mononuclear cells (PBMCs) are increased by $0.1-10 \mathrm{nM}$ estradiol and are sustained at concentrations of estradiol higher than $10 \mathrm{nM}$ after 7 days in culture (5).

Nagata et al. reported that Graves' disease patients and healthy controls have Epstein-Barr virus (EBV)-infected lymphocytes with thyrotropin receptor antibody (TRAb) on their surface (TRAb(+)EBV $(+)$ cells) in PBMCs, and these PBMCs produce TRAb in response to reactivation of EBV in vitro $(11,13)$. Nagata et al. also reported that there is a

\footnotetext{
${ }^{1}$ Division of Molecular Pathology, Department of Pathology, Faculty of Medicine, Tottori University, Yonago, Japan.

${ }^{2}$ Department of Pathobiological Science and Technology, School of Health Science, Tottori University, Yonago, Japan.

(C) Sayuri Hara et al., 2018; Published by Mary Ann Liebert, Inc. This Open Access article is distributed under the terms of the Creative Commons Attribution Noncommercial License (http://creativecommons.org/licenses/by-nc/4.0/), which permits any noncommercial use, distribution, and reproduction in any medium, provided the original author(s) and the source are cited.
} 
positive relationship between serum levels of TRAb and the EBV-early antigen antibody, a marker of EBV reactivation (10). Therefore, EBV reactivation may contribute to autoantibody production. Graves' disease, an autoimmune hyperthyroidism, is caused by TRAb, which overstimulates thyroid stimulating hormone receptor (8).

We examined the effects of estradiol on antibody production induced by EBV reactivation in PBMCs of healthy controls and Graves' disease patients. We used 0, 1, and $100 \mathrm{nM}$ concentrations of estradiol, corresponding to control, midluteal phase, and pregnancy levels, respectively. We discuss the effects of estradiol levels in the menstrual cycle and pregnancy on EBV reactivation-induced antibody production.

\section{Materials and Methods}

\section{Subjects}

PBMC samples were obtained from seven Graves' disease patients and eight healthy controls (Table 1). All subjects provided written informed consent, and the study protocol was approved by the Medical Ethics Committee for Human Subject Research (No. 707, 707-1-13) at the Faculty of Medicine, Tottori University, Yonago, Japan. The mean ages $( \pm \mathrm{SD})$ of healthy controls and Graves' disease patients were $29.75( \pm 10.89)$ years and $40.00( \pm 6.22)$ years, respectively. All subjects were female. At the time of diagnosis, patients exhibited symptoms and had laboratory data that included at least one of the following: (1) signs of thyrotoxicosis such as tachycardia, weight loss, finger tremors, and sweating; (2) diffuse enlargement of the thyroid gland; and (3) exophthalmos and/or specific ophthalmopathy. All patients met the following criteria: (1) elevated serum levels of free T4 and/or free T3; (2) suppression of serum thyrotropin (thyroid stimulating hormone: TSH) $(<0.1 \mu \mathrm{U} / \mathrm{mL})$; and (3) positivity for TRAb or thyroid-stimulating antibody. Five of the seven patients were receiving treatments with antithyroid drugs (methylmercaptoimidazole or propylthiouracil). Three patients were receiving treatments with levothyroxine and No. 11 patient was treated with only levothyroxine. Control subjects were enrolled voluntarily, their thyroid functions were normal, and they had no family history of thyroid disease.

\section{PBMC preparation}

Peripheral blood samples were obtained from Graves' disease patients and healthy controls. PBMCs were separated using a Ficoll-Conray density gradient and stored at $-80^{\circ} \mathrm{C}$ until use.

\section{Estradiol}

17ß-estradiol (Sigma-Aldrich, Saint Louis, MO) was dissolved in ethanol to prepare a $1 \mathrm{mg} / \mathrm{mL}$ stock solution and stored at $4{ }^{\circ} \mathrm{C}$ until use. Estradiol was added to medium and maintained at 0,1 , or $100 \mathrm{nM}$, corresponding to control, midluteal, or pregnancy levels, respectively. Except for doses of estradiol, every culture was performed with the same medium, and we confirmed that the estradiol concentration of the medium was neglectable.

\section{Sampling protocol}

PBMCs were cultured at $37^{\circ} \mathrm{C}$ for 2 days in RPMI 1640/ $10 \%$ FBS with cyclosporin A $(0.1 \mu \mathrm{g} / \mathrm{mL})$ to inhibit $\mathrm{T}$ cell effects. PBMCs were transferred to an incubator at $33^{\circ} \mathrm{C}$ to induce EBV reactivation and were regarded as day 0 samples. On days $0,5,10$, and 12 , half of the culture supernatant was sampled and replaced by fresh medium with estradiol, and the estradiol concentration was maintained at 0,1 , or $100 \mathrm{nM}$.

\section{Measurement of total immunoglobulin}

Immunoglobulin ( $\mathrm{Ig}$ ) concentrations in culture supernatant were measured by ELISA. The total IgG and IgM concentrations were measured using a Human IgG/IgM ELISA Quantitation Set (Bethyl Laboratories, Montgomery, TX).

Table 1. Subject Profiles

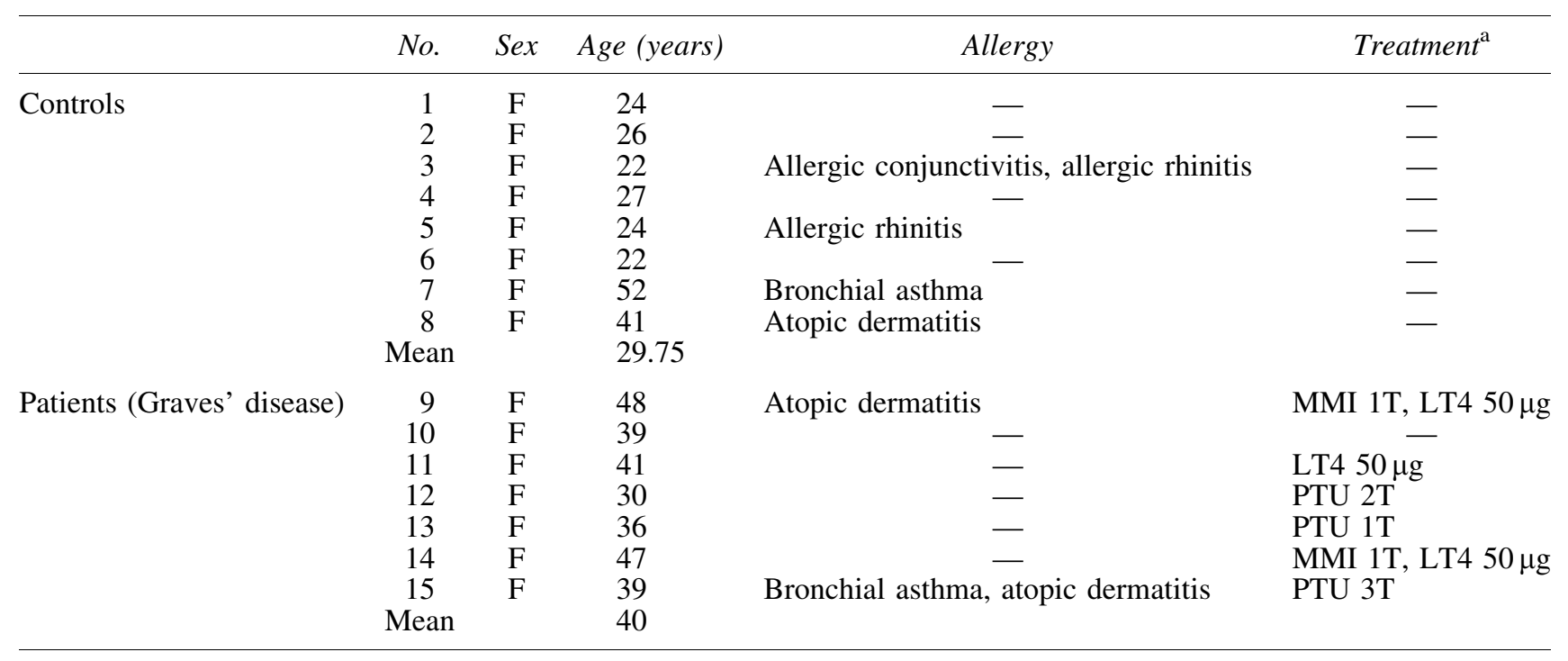

'Treatment for patients with Graves' disease.

LT4, levothyroxine; MMI, methylmercaptoimidazole; PTU, propylthiouracil. 


\section{Determination of TRAb concentration}

TRAb concentration in culture fluids was quantified by a radioreceptor assay according to the manufacturer's instructions (DYNOtest TRAb Human; Yamasa Corporation, Choshi, Japan).

\section{Statistical analyses}

SPSS Statistics 21 (IBM, Armonk, NY) was used for statistical analyses. A Mann-Whitney $U$ test was adopted for comparisons between Graves' disease patients and healthy controls. The Wilcoxon rank sum test was used for the analyses of the effects of estradiol compared with that of baseline ( $0 \mathrm{nM}$ estradiol).

\section{Results}

\section{Effect of estradiol on EBV reactivation-induced Ig production}

TRAb production. Compared with TRAb production in the culture at $0 \mathrm{nM}$ estradiol, means of TRAb production were increased with $1 \mathrm{nM}$ estradiol and decreased with $100 \mathrm{nM}$ in healthy controls and patients, although the differences were not statistically significant. There were no significant differences between healthy controls and patients in TRAb production at each estradiol concentration (Fig. 1).

IgG production. The concentration of estradiol did not have a significant effect on IgG production in healthy controls or patients. There were no significant differences in IgG production at each estradiol concentration between healthy controls and patients (Fig. 2).

IgM production. In patients, IgM production at $100 \mathrm{nM}$ estradiol was significantly lower than that at $0 \mathrm{nM}$ estradiol $(p=0.028)$. There were no significant differences in $\operatorname{IgM}$ production at each concentration of estradiol between healthy controls and patients (Fig. 3).

\section{Effect of estradiol on the ratio of $\lg G$ to $\lg G$ and $\lg M$}

Figure $4 \mathrm{a}$ and $\mathrm{b}$ is a pileup of mean $\operatorname{IgG}$ and $\mathrm{IgM}$ production to overview the ratio of $\mathrm{IgG}$ production. Estradiol increased the mean production of $\mathrm{IgG}$ in controls (Fig. 4a) and decreased the mean production of IgM in patients (Fig. 4b).

To perform statistical analyses, we calculated the ratio of IgG production to the sum of IgG and IgM production (IgG/ $\operatorname{IgG}+\operatorname{IgM})$ as for every sample of controls and patients (Fig. 4c, d). In patients, we detected the trend of an increase in the ratio of $\operatorname{IgG} / \mathrm{IgG}+\operatorname{IgM}$ between 0 and $1 \mathrm{nM}$ estradiol $(p=0.063)$ and between 0 and $100 \mathrm{nM}$ estradiol $(p=0.128)$ (Fig. 4d), but there were no significant differences (Fig. 4d). There were no significant differences in the ratio of $\mathrm{IgG} / \mathrm{IgG}$ + IgM between healthy controls and patients at each concentration of estradiol (Fig. 5).

\section{Discussion}

Similar to previous reports (11-13), we found that EBV reactivation induced production of $\mathrm{IgG}, \mathrm{IgM}$, and TRAb in the supernatants of PBMCs from Graves' disease patients and healthy controls (Figs. 1-3). We observed that $1 \mathrm{nM}$ estradiol considerably increased TRAb levels and $100 \mathrm{nM}$ estradiol slightly lowered them in both patients and controls (Fig. 1), although the differences were not statistically significant. TRAb production was stimulated by a midluteal level of estradiol and suppressed by a pregnant level of estradiol, but the difference was not significant probably because there were only a few subjects and large differences in TRAb production between individuals. In a study of menstrual cycle, we often realize the large individual difference probably derived from the number or function of ERs in each subject, as well as the cyclicity of estrogen and progesterone secretion (1-3). The increase in TRAb at midluteal level of estradiol matches
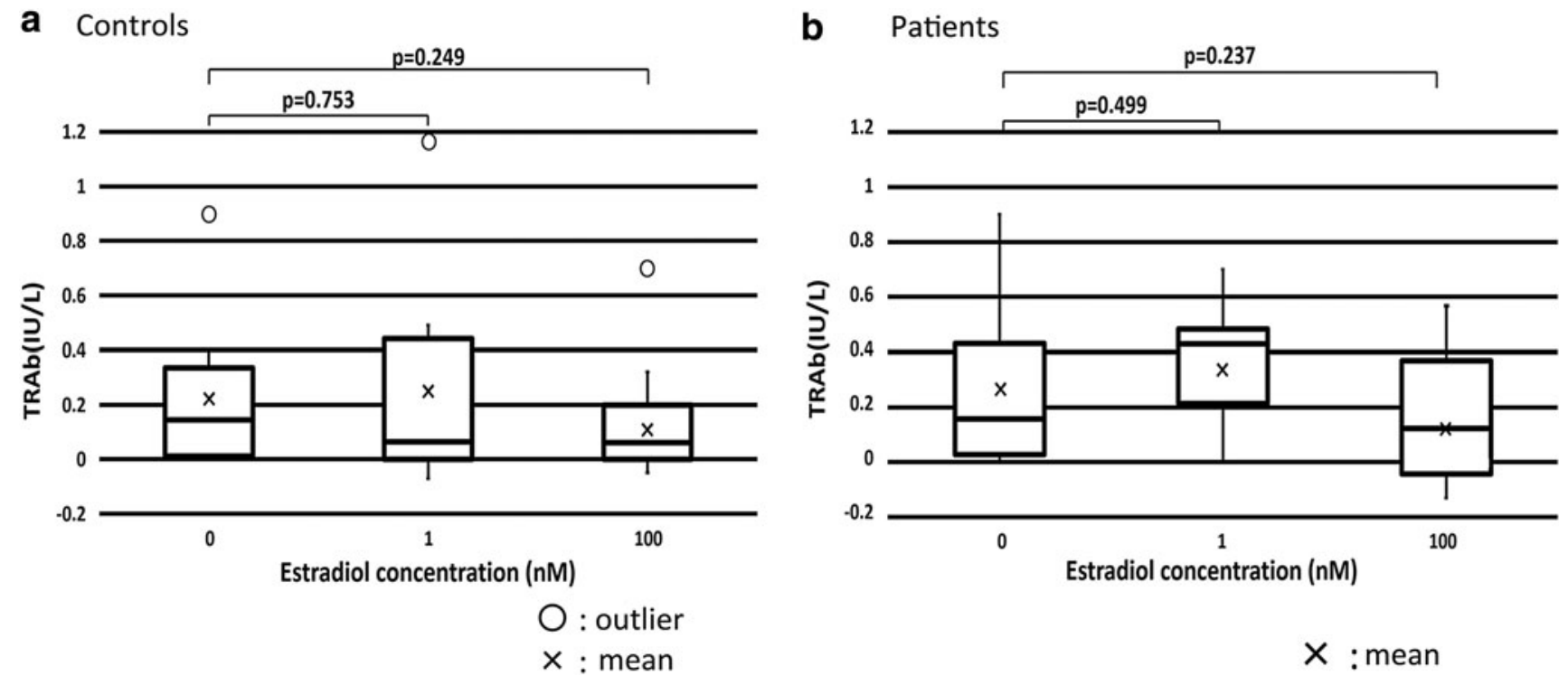

FIG. 1. TRAb production was increased by $1 \mathrm{nM}$ estradiol and decreased by $100 \mathrm{nM}$ estradiol in healthy controls and patients, but differences were not significant. (a) Mean TRAb production in healthy controls. (b) Mean TRAb production in patients. TRAb, thyrotropin receptor antibody. 


\section{a Controls}

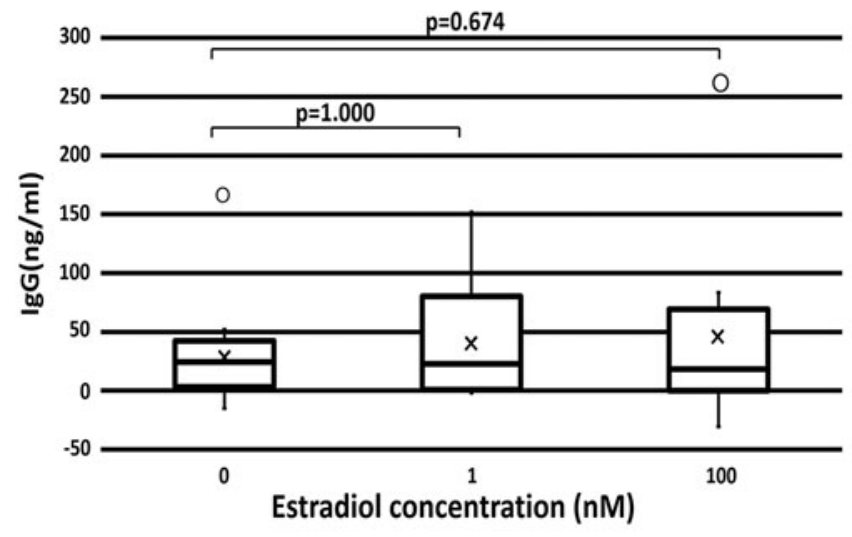

$\bigcirc$ : outlier

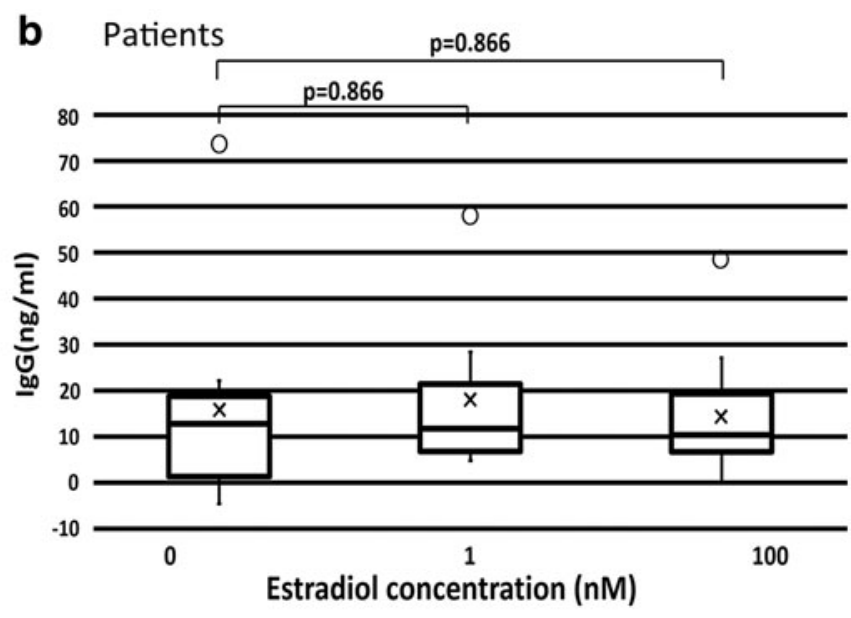

: outlier

$x$ : mean

FIG. 2. The concentration of estradiol did not significantly affect IgG production in healthy controls and patients. (a) Mean IgG production in healthy controls. (b) Mean IgG production in patients. IgG, immunoglobulin G.

premenstrual worsening of autoimmune diseases, including Graves' disease $(7,15,18)$. On the contrary, TRAb suppression by a pregnant level of estradiol is consistent with the improvement of autoimmune diseases, including Graves' disease in maternity (8).

In patients, IgM production at $100 \mathrm{nM}$ estradiol was significantly lower than that at $0 \mathrm{nM}$ estradiol $(p=0.028)$, which suggested a relative increase in IgG. In particular, estradiol increased the ratio of $\mathrm{IgG} / \mathrm{IgG}+\mathrm{IgM}$ in both patients and healthy controls. In patients, the $\operatorname{IgG} / \mathrm{IgG}+\operatorname{IgM}$ ratio increased between 0 and $1 \mathrm{nM}$ estradiol $(p=0.063)$ and between 0 and $100 \mathrm{nM}$ estradiol ( $p=0.128)$, but there were no differences in control patients (Fig. 4).

When persistent EBVs are reactivated, host B cells differentiate into plasma cells and produce various isotypes of
$\mathrm{Ig}$, which is the result of class switch recombination (CSR) during Ig production because naive B cells have IgM on their surface. CSR replaces the Ig heavy chain and switches the Ig isotype from IgM to high affinity Ig (9). In EBV reactivation-induced Ig production, expression of activationinduced cytidine deaminase (AID) is induced by EBV-LMP1 (12). Therefore, Ig production involves AID expression and subsequent CSR. An increase in the ratio of $\operatorname{IgG} / \mathrm{IgG}+\operatorname{IgM}$ may result from increased IgG production due to AID induction and CSR. Estrogen binds to the ER and the estrogenER complex binds to the Ig gene heavy chain locus in B cells, stimulating antibody expression and CSR (4). Moreover, the estrogen-ER complex binds to the AID promoter and increases AID protein production (17). We observed that estradiol increased the ratio of $\operatorname{IgG} / \mathrm{IgG}+\mathrm{IgM}$, a Controls

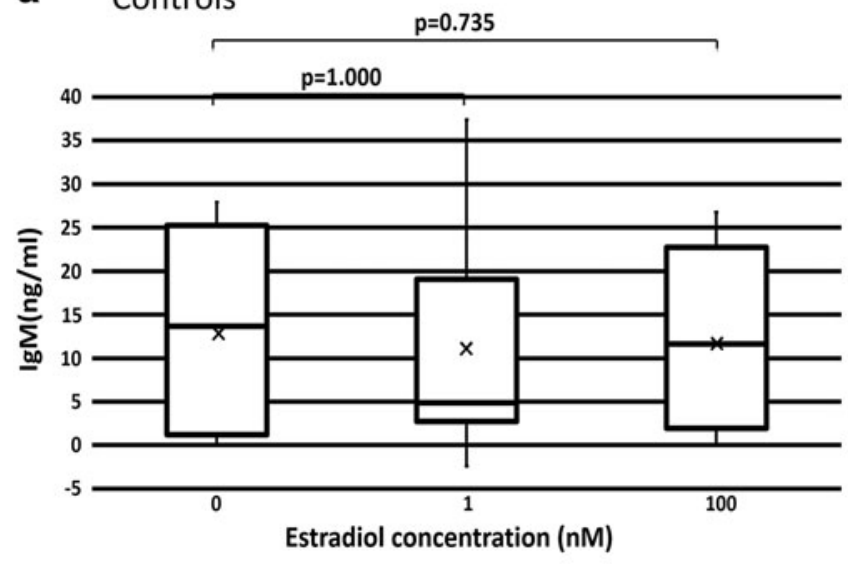

$X$ : mean b Patients

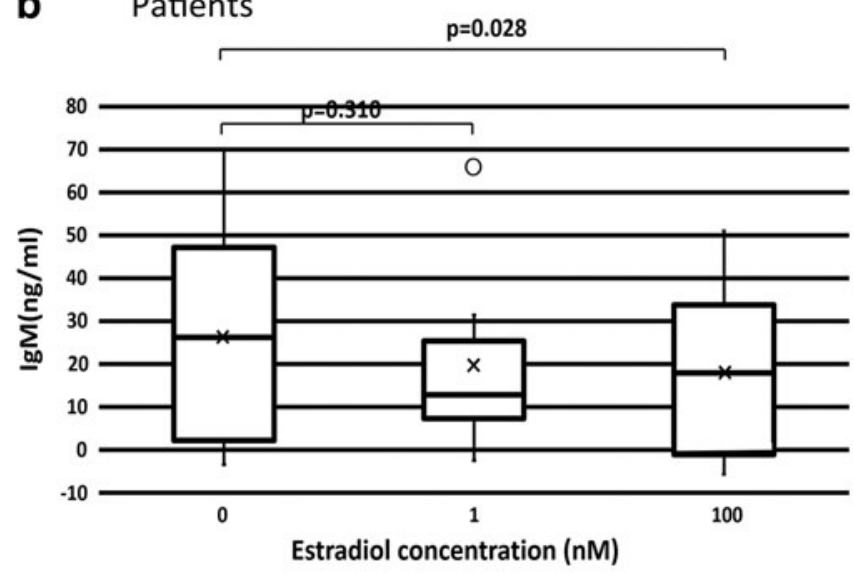

$$
\begin{aligned}
& O \text { : outlier } \\
& \times \text { : mean }
\end{aligned}
$$

FIG. 3. IgM production was decreased by $100 \mathrm{nM}$ estradiol. (a) Mean IgM production in healthy controls. (b) Mean IgM production in patients. IgM production at $100 \mathrm{nM}$ estradiol was significantly lower than that at $0 \mathrm{nM}$ estradiol $(p=0.028)$. IgM, immunoglobulin M. 
a

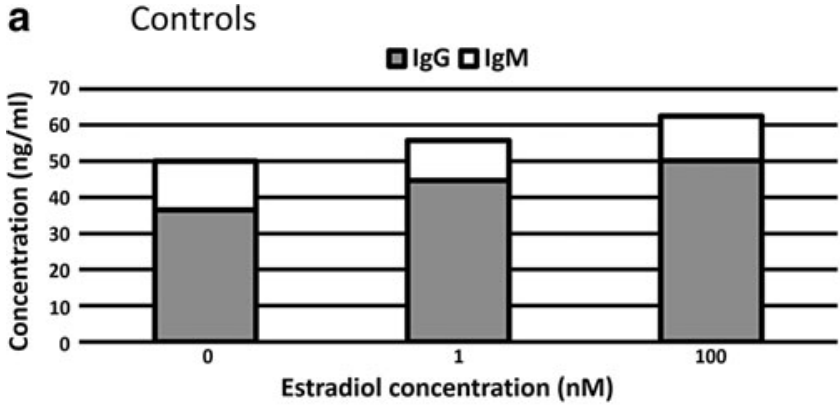

C Controls (IgG/IgG + IgM)

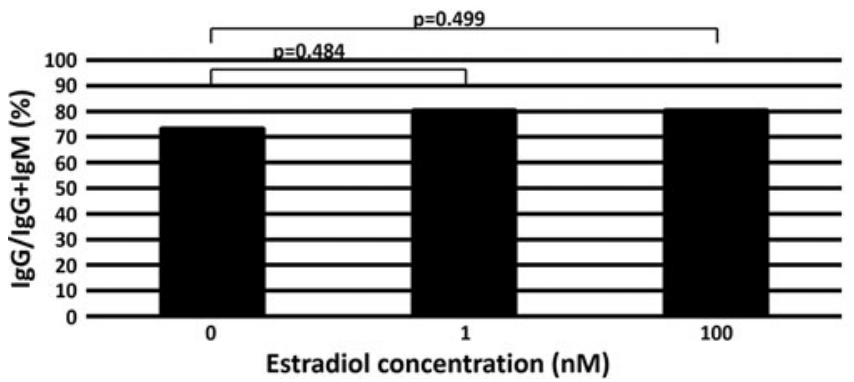

b Patients

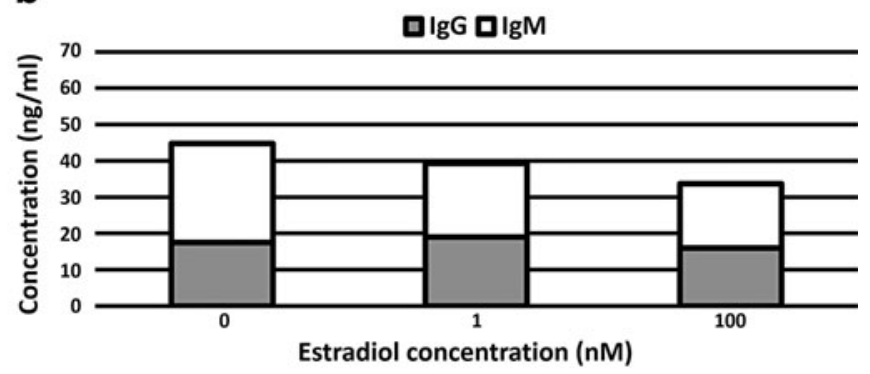

Patients (IgG/ IgG + IgM)

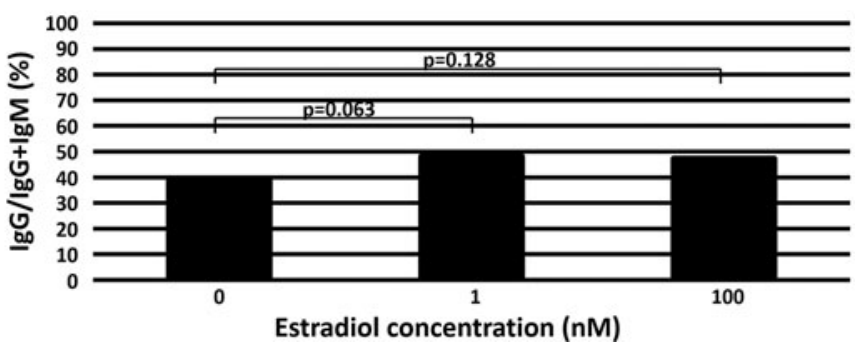

FIG. 4. Estradiol increased the ratio of $\operatorname{IgG}$ to $\operatorname{IgG}$ and $\operatorname{IgM}(\operatorname{IgG} / \operatorname{IgG}+\operatorname{IgM})$ in patients. Pileup production of $\operatorname{Ig}$ in healthy controls (a) and patients (b). The ratio of IgG to IgG and IgM (IgG/IgG + IgM) in healthy controls (c) and patients (d). In patients, the $\mathrm{IgG} / \mathrm{IgG}+\mathrm{IgM}$ ratio increased between 0 and $1 \mathrm{nM}$ estradiol $(p=0.063)$ and between 0 and $100 \mathrm{nM}$ estradiol $(p=0.128)$.

which suggests that estradiol increased CSR in the process of EBV reactivation-induced Ig production.

The ratio of $\mathrm{IgG} / \mathrm{IgG}+\mathrm{IgM}$ in controls was higher than that in patients at all three concentrations of estradiol. However, there were no significant differences between patients and healthy controls at each concentration probably because of a small sample size and large individual differences in controls. EBV reactivation-induced Ig production is influenced by how easily persistent EBV is reactivated. EBV serum antibodies are high in patients with allergies and autoimmune diseases $(7,15)$. Therefore, allergen history is important for selecting control subjects, and examination of how estradiol directly affects EBV reactivation is needed.
In this study, we examined the tonic effect of estradiol on B cell in vitro although estradiol may have a tonic and cyclic effect on B cell in vivo, for instance, estradiol levels fluctuate during menstrual cycle (1). Therefore, we should investigate further possibility between estradiol and B cell, including the estradiol withdrawal test. Estrogen affects various cells through multiple pathways $(2,6)$. B cells are known to be ERpositive cells, but the receptor number and function may be different individually, similar to mammary glandular cells $(1,3)$. This might be one of the causes of individual difference.

Two of our seven patients (No. 10,11) were not treated with antithyroid drugs. The levels of TRAb released in culture mediums were lower in No. 11 treated with only

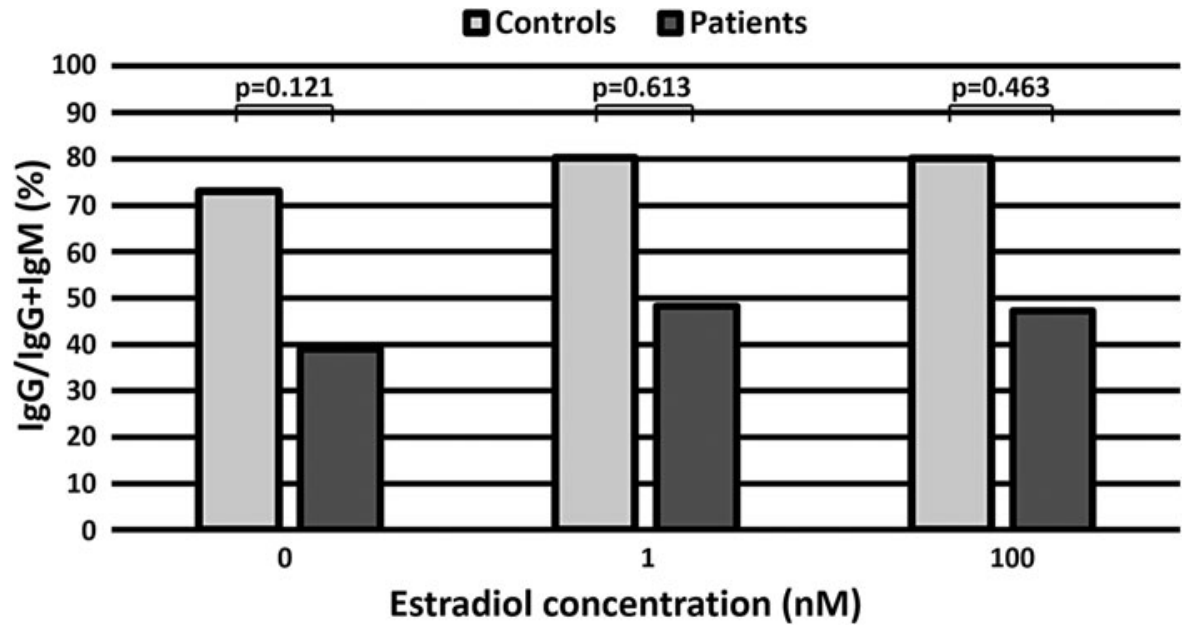

FIG. 5. The effect of estradiol on the ratio of $\operatorname{IgG}$ to $\operatorname{IgG}$ and $\operatorname{IgM}(\operatorname{IgG} / \operatorname{IgG}+\operatorname{IgM})$ in healthy controls and patients. There were no significant differences between healthy controls and patients for each concentration of estradiol. 
levothyroxine than the means of patients in every estradiol concentration, but in No. 10 without treatment, they were higher.

Antithyroid drugs are reported to have immunomodulatory effects and that is because the patients receiving antithyroid drug show lowered serum TRAb levels (clinical observation). These are also future tasks.

In conclusion, we examined the effect of estradiol on EBV reactivation-induced Ig production, an alternative system of antibody production. Because of a small sample size and individual difference, including the numbers and function of ER, we did not observe sufficiently significant differences. However, we detected a significant decrease in IgM production at $100 \mathrm{nM}$ estradiol in patients and showed the trend that estradiol increased the ratio of $\mathrm{IgG} / \mathrm{IgG}+\mathrm{IgM}$, which suggests that estradiol increased CSR. Furthermore, $1 \mathrm{nM}$ estradiol (the midluteal level) may have the effect to increase TRAb production and $100 \mathrm{nM}$ estradiol (the pregnancy level) may suppress TRAb production. These results are consistent with clinical observations of premenstrual worsening and maternity improving of autoimmune disease, including Graves' disease $(7,15,18)$.

\section{Acknowledgments}

We are grateful to the laboratory staff of Molecular Pathology Division, Tottori University. This work was supported by JSPS KAKENHI Grant No. 17K08694 (K.N.).

\section{Author Disclosure Statement}

No competing financial interests exist.

\section{References}

1. Allred DC, Brown P, and Medina D. The origins of estrogen receptor alpha-positive and estrogen receptor alpha-negative human breast cancer. Breast Cancer Res 2004;6:240-245.

2. Annalisa T, Serena T, Carlotta B, et al. Estrogen, angiogenesis, immunity and cell metabolism: solving the puzzle. Int J Mol Sci 2018;19:859

3. Early Breast Cancer Trialists' Collaborative Group (EBCTCG). Relevance of breast cancer hormone receptors and other factors to the efficacy of adjuvant tamoxifen: patient-level meta-analysis of randomised trials. Lancet 2011;378:771-784.

4. Jones BG, Penkert RR, Xu B, et al. Binding of estrogen receptors to switch sites and regulatory elements in the immunoglobulin heavy chain locus of activated B cells suggests a direct influence of estrogen on antibody expression. Mol Immunol 2016;77:97-102.

5. Kanda N, and Tamaki K. Estrogen enhances immunoglobulin production by human PBMCs. J Allergy Clin Immunol 1999;103:282-288.

6. Khan D, and Ansar Ahmed S. The immune system is a natural target for estrogen action: opposing effects of estrogen in two prototypical autoimmune diseases. Front Immunol 2016;6:635.

7. Longnecker RM, Kieff E, and Cohen J. Epstein-Barr virus. In: Knipe DM, Howley PM, eds. Fields Virology. 6. Phi- ladelphia: Lippincott Williams \& Wilkins, 2013:18981959.

8. Mandel SJ, Larsen PR, and Davies TF. Thyrotoxicosis. In: Melmed S, Polonsky KS, Larsen PR, and Kronenberg HM, eds. Williams Textbook of Endocrinology, 12th ed. Philadelphia: Saunders, 2011:362-405.

9. Muramatsu M, Kinoshita K, Fagarasan S, et al. Class switch recombination and hypermutation require activation-induced cytidine deaminase (AID), a potential RNA editing enzyme. Cell 2000;102:553-563.

10. Nagata K, Fukata S, Kanai K, et al. The influence of Epstein-Barr virus reactivation in patients with Graves' disease. Viral Immunol 2011;24:143-149.

11. Nagata K, Higaki K, Nakayama Y, et al. Presence of Epstein-Barr virus-infected B lymphocytes with thyrotropin receptor antibodies on their surface in Graves' disease patients and in healthy individuals. Autoimmunity 2014;47: 193-200.

12. Nagata K, Kumata K, Nakayama Y, et al. Epstein-Barr virus lytic reactivation activates $\mathrm{B}$ cells polyclonally and induces activation-induced cytidine deaminase expression: a mechanism underlying autoimmunity and its contribution to Graves' disease. Viral Immunol 2017;30:240-249.

13. Nagata K, Nakayama Y, Higaki K, et al. Reactivation of persistent Epstein-Barr virus (EBV) causes secretion of thyrotropin receptor antibodies (TRAbs) in EBV-infected B lymphocytes with TRAbs on their surface. Autoimmunity 2015;48:328-335.

14. Ngo ST, Steyn FJ, and McCombe PA. Gender differences in autoimmune disease. Front Neuroendocrinol 2014;35: 347-369.

15. Okudaira H, Shuto H, Shuto C, et al. A shadow of EpsteinBarr virus in the pathogenesis of atopic diseases. Clin Exp Allergy 2001;31:18-24.

16. Ortona E, Pierdominici M, Maselli A, et al. Sex-based differences in autoimmune diseases. Ann Ist Super Sanita 2016;52:205-212.

17. Pauklin S, Sernández IV, Bachmann G, Ramiro AR, and Petersen-Mahrt SK. Estrogen directly activates AID transcription and function. J Exp Med 2009;206:99-111.

18. Pearlstein T, and Stone AB. Premenstrual syndrome. Psychiatr Clin N Am 1998;21:577-590.

19. Steinberg AD, Melez KA, Raveche ES, et al. Approach to the study of the role of sex hormones in autoimmunity. Arthritis Rheum 1979;22:1170-1176.

20. Straub RH. The complex role of estrogens in inflammation. Endocr Rev 2007;28:521-574.

Address correspondence to: Prof. Kazuhiko Hayashi Division of Molecular Pathology Department of Pathology Faculty of Medicine Tottori University 86 Nishi-cho Yonago 683-8503 Japan

E-mail: hayashik@med.tottori-u.ac.jp 